\section{Editor-in-Chief \\ Barbara McLain - (retired Prof.) \\ University of Hawaii, USA}

The Israeli Journal of Aquaculture (IJA) is an interdisciplinary journal that is dedicated to sharing new research and tested applications of aquaculture

The IJA is devoted to scholarly articles for improved aquaculture practices and related industries

The IJA is a peer-reviewed, open-access, electronic journal

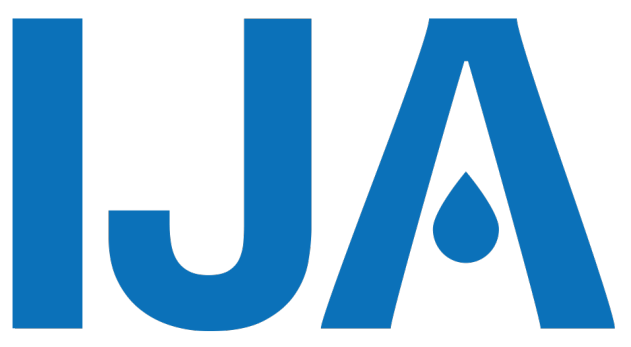

\section{The () Israeli Journal of Aquaculture}

An interdisciplinary online Open Access scientific journal

Published by the

\section{AquacultureHub}

A non-profit organization 501c3

http://www.aquaculturehub.org

in partnership with the

\section{University of Hawaii at Manoa} Library

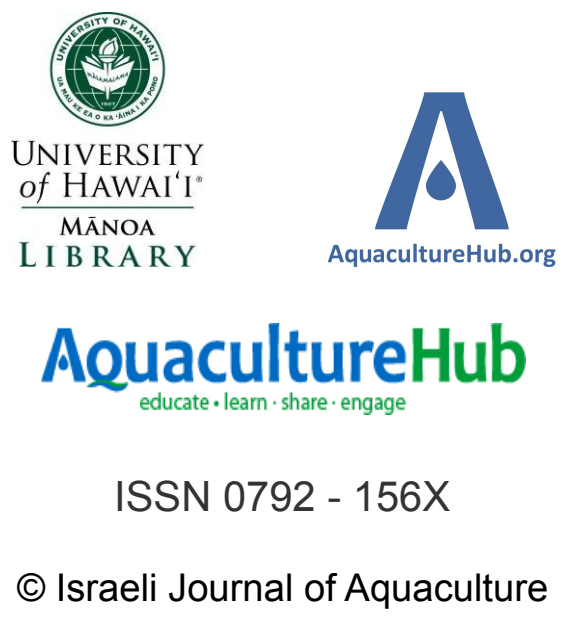




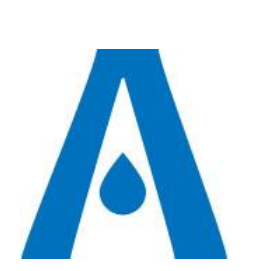

Produced by the AquacultureHub non-profit Foundation the $I J A$ is an open-access, scientific journal, published on http://www.aquaculturehub.org/group/israelijournalofaq uaculturebamidgehija

To read papers free of charge, please register online at the above website.

Sale of $I J A$ papers is strictly forbidden.

\title{
Inhibitory Effects of Galla chinensis, Tannic Acid, and Gallic Acid on Saprolegnia parasitica
}

\author{
Zhang $\mathrm{QQ}^{1}$, Li AH ${ }^{1}$, Liu $\mathrm{LH}^{2}$ \\ ${ }^{1}$ Fish Disease Laboratory, State Key Laboratory of Freshwater Ecology and \\ Biotechnology, Institute of Hydrobiology, Chinese Academy of Sciences, \\ Wuhan 430072, People's Republic of China \\ ${ }^{2}$ Key Laboratory of Fishery Drug Development, Ministry of Agriculture, Key \\ Laboratory of Aquatic Animal Immune Technology, Guangdong Province, \\ Pearl River Fishery Research Institute, Chinese Academy of Fishery \\ Sciences, Guangzhou 510380, People's Republic of China
}

Keywords: Galla chinensis; tannic acid; gallic acid; Saprolegnia parasitica

\begin{abstract}
The inhibitory effects of Galla chinensis and its two main ingredients, tannic acid and gallic acid, on Saprolegnia parasitica were examined, using the method of agar plate assay and liquid dilution assay. The results showed that all the three tested drugs had different degrees of inhibitory activity on mycelial growth and zoospore germination of Saprolegnia parasitica, with tannic acid showing the most significant inhibition. The mycelial growth of $S$. parasitica was completely inhibited by tannic acid at the concentration of more than $32 \mathrm{mg} / \mathrm{L}$, and the germination rate of S. parasitica zoospores decreased by $66 \%$ at a concentration of $5 \mathrm{mg} / \mathrm{L}$. Considering the low cost of tannic acid together with its inhibitory effect on S. parasitica, tannic acid showed the most significant potential in the prevention and control of fish saprolegniasis.
\end{abstract}

* Corresponding author: Aihua Li, Tel: 86-27-68780053;

Fax number: 86 027-68780053; email address: liaihua@ihb.ac.cn, 


\section{Introduction}

Saprolegniasis, caused by water molds, is widespread in freshwater and represents the most common fungal infection affecting wild and cultured aquatic animals (Neish et al., 1980; Srivastava, 1987; Webster, 1998), especially fish and amphibians. Saprolegnia parasitica (Saprolegniaceae, Saprolegniales, oomycetes), which is one of the most common causative agents of fish saprolegniasis, is responsible for severe damage in all development stages of almost all aquaculture animals, and due to its extensive transmissibility and lack of selectivity to the host, this disease frequently causes considerable economic problems in the fish farming industry (Hussein and Hatai, 2002). In many countries in the past, malachite green was often applied to control saprolegniasis (Pottinger and Day, 1999). For many years, its use on aquatic comestible animals has been prohibited in most countries including China due to its severe toxicity to humans, and to the environment (Meyer and Jorgenson, 1983; Srivastava et al., 2004); it has been listed on the List of Prohibited Animal drugs. Until now no comparably effective and practicable legal alternatives to be used for the treatment of this ailment in aquaculture have been developed.

Chinese gall (Galla chinensis), is a plant excretory product produced when irritants are released by the larvae of gall insects (Chinese Pharmacopoeia Commission, 2010). The major sources of medicinal gallnuts are Rhus Chinese Mill, Rhus potaninii Maxim, and Rhus punjabensis Stew.var.sinica (Diels) Rehd.et Wils. Chinese gall which is considered to possess strong bacteriostatic and bactericidal activity, is a common medicine in aquaculture, mainly applied to control saprolegniasis, red skin disease, aemmonasis, white skin disease, pseudomonas, and furunculosis. Chinese gall contains the highest naturally occurring level of tannic acid (TA) up to $80 \%$ (Qiao et al., 2011) and 2 4\% of the smaller molecules gallic acid (GA). The tannins possess significant biological properties such as antimicrobial, antiviral (Orlowski et al., 2014), antioxidant (Andrade Jr et al., 2005), anti-inflammatory, and anti-parasitic activities (Pérez-Fonseca et al., 2016). GA is a natural polyphenol, which shows a strong biological activity including antioxidant and antibacterial properties (Zheng et al., 2010).

To the best of our knowledge, there is little, or no information and experimental evidence related to the effect of Chinese gall, gallic acid, and tannic acid on Saproleginasis parasitica. In the present study, the in vitro antifungal effects of Chinese gall and its two extracts for controlling of $S$. parasitica were investigated and evaluated.

\section{Materials and methods}

Chinese gall (Galla chinensis) was purchased from Beijing Tong Ren Tang Chinese Medicine Co., Ltd. and conformed to China's pharmacopeia (2010 version) standards. TA and GA were provided by Wufeng Chicheng Biotech Co., Ltd with the contents of $83 \%$ and $88 \%$, respectively.

Preparation of Chinese gall water extract (CgWE).

Chinese gall powder was crushed and then $2.0 \mathrm{~g}$ was soaked in $100 \mathrm{~mL}$ distilled water overnight at $4^{\circ} \mathrm{C}$ and then boiled for $1 \mathrm{~h}$. After centrifugation at $8000 \mathrm{rpm}$, the supernatant was filtered through $0.22 \mu \mathrm{m}$ sterile filter membrane and the final concentration was adjusted to $100 \mathrm{mg} / \mathrm{mL}$. Malachite green (MG) was employed as positive anti-mold control. Three concentrations, $100 \mathrm{mg} / \mathrm{mL}, 10 \mathrm{mg} / \mathrm{mL}$, and $1 \mathrm{mg} / \mathrm{mL}$, of MG, TA, and GA were prepared with distilled water and then filtered through $0.22 \mu \mathrm{m}$ sterile filter membrane.

Saprolegnia parasitica and mycelium cultivation.

Saprolegnia parasitica (ATCC 200013) was used as the target organism in the assays. Mycelia of $S$. parasitica were routinely grown in potato dextrose agar (PDA) medium for three days at $20^{\circ} \mathrm{C}$.

\section{Antifungal susceptibility related to mycelium growth inhibition}

Disc diffusion assay.

The minimal inhibitory concentrations of CgWE, TA, GA, and MG were tested using the disc diffusion method according to the National Committee for Clinical Laboratory Standards Institute (CLSI) Guidelines. The crystallized mother liquors of three drugs was added to the autoclaved PDA medium in different proportions, making a series of plates. The concentration of Chinese gall, TA, and GA, ranged from 1 to $4096 \mathrm{mg} / \mathrm{L}$. Negative 
controls were set up using plain Potato Dextrose Agar (PDA) plates without any drug supplement, positive controls were set up using PDA plates with final concentrations of $16,8,4,2,1,0.5 \mathrm{mg} / \mathrm{L}$ of MG. The $9 \mathrm{~mm}$ diameter inocula were obtained by taking mycelium-bearing agar cylinders from the peripheral area of the culture with a sterile scalpel and placed the inocula on top of PDA agar (Fig. 1) and incubated at $20^{\circ} \mathrm{C}$ for $48 \mathrm{~h}$.

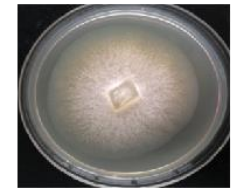

MG $0.5 \mathrm{mg} / \mathrm{L}$

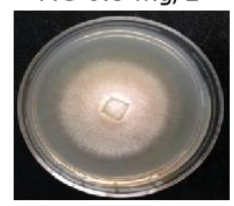

CgWE 64 mg/L

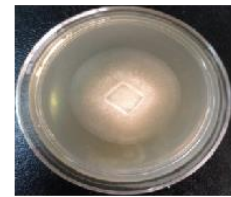

GA $512 \mathrm{mg} / \mathrm{L}$

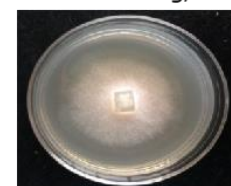

TA $32 \mathrm{mg} / \mathrm{L}$

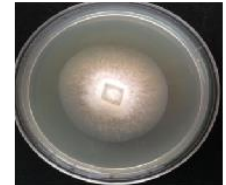

MG $1 \mathrm{mg} / \mathrm{L}$

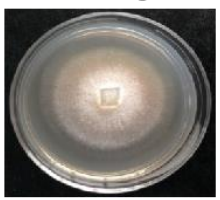

CgWE 128 mg/L

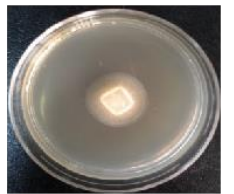

GA $1024 \mathrm{mg} / \mathrm{L}$

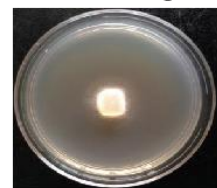

TA $64 \mathrm{mg} / \mathrm{L}$

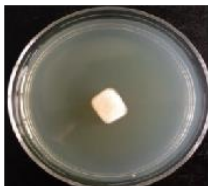

MG $2 \mathrm{mg} / \mathrm{L}$

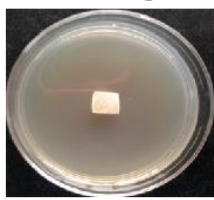

CgWE 256 mg/L

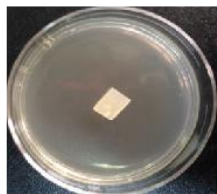

GA $2048 \mathrm{mg} / \mathrm{L}$

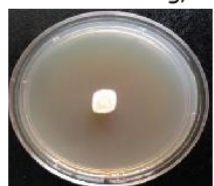

TA 128 mg/L

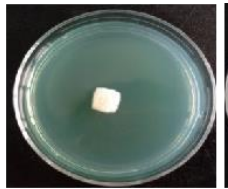

MG $4 \mathrm{mg} / \mathrm{L}$

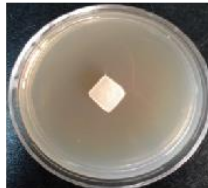

CgWE 512 mg/L

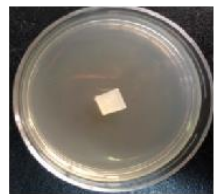

GA $4096 \mathrm{mg} / \mathrm{L}$

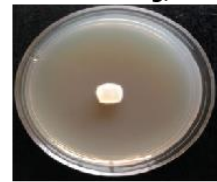

TA $256 \mathrm{mg} / \mathrm{L}$

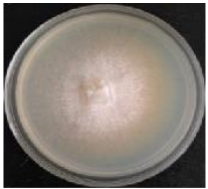

Blank control

Fig. 1. Mycelium growth performance of $S$. parasitica on PDA agar containing four drugs of different concentrations at $20{ }^{\circ} \mathrm{C} 60 \mathrm{~h}$ after inoculation

The growth of the mycelium on the agar plates was then observed. The minimal inhibitory concentration (MIC) with no mycelium growth was considered the lowest drug concentration. The percentage inhibition of radial growth (PIRG) assay, the mycelium was recorded after $60 \mathrm{~h}$ when the control plate of $S$. parasitica was spread to the margin of the plate. The inhibition growth was calculated based on PIRG (\%) as follows:

PIRG $(\%)=[(R 1-R 2) / R 1] \times 100 \%$,

where, $\mathrm{R} 1=$ radial growth diameter of control plate, and $\mathrm{R} 2=$ radial growth diameter of treatment plate (Shin et al., 2017). Experiments were performed in triplicate.

Liquid dilution assay.

The mycelium-bearing agar cylinders, diameter of $9 \mathrm{~mm}$, were obtained using a sterile scalpel, and placed into the wells of a 24-well flat-bottom tissue culture plate, 2 $\mathrm{mL}$ aliquots from a 2-fold serial dilution of tested drugs were added to the wells. Positive control wells that received MG starting from $16 \mathrm{mg} / \mathrm{L}$, as well as negative controls that received sterile water, were included in each plate. Plates were incubated at $20^{\circ} \mathrm{C}$ for $24 \mathrm{~h}$.

Antifungal susceptibility related to spore germination inhibition

Zoospore suspension preparation.

Three $9 \mathrm{~mm}$ diameter inocula were added to wells of an 8-well flat bottom tissueculture plate, and $6 \mathrm{~mL}$ filtered sterile water was added to each well. The 8-well plate was placed in an incubator at $20^{\circ} \mathrm{C}$ until most of the zoospores were released. Zoospore suspension was obtained by filtering the water through three layers of sterile gauze after vortex shock for 3-5 s to make the zoospore dispersive. The zoospore concentration was estimated with a hemocytometer, and their concentration was adjusted to $10^{3}$ per milliliter. 
Disc diffusion assay.

The preparation of PDA plates with different concentrations of drugs referred to the aforementioned concentrations in 'Antifungal susceptibility related to mycelium growth inhibition'. $150 \mu \mathrm{L}$ zoospore suspension was spread onto the surface of PDA agar and allowed to incubate at $20^{\circ} \mathrm{C}$ for $48 \mathrm{~h}$. The growth of mycelia on agar was observed.

Liquid dilution assay.

The spore suspension was inoculated into a 96-well plate with $100 \mu \mathrm{L}$ in each well, then $100 \mu \mathrm{L}$ test drugs were added. Positive control wells were added $100 \mu \mathrm{L}$ aliquots from a 10 -fold serial dilution of tested drugs starting from $50 \mathrm{mg} / \mathrm{L}$ to $0.005 \mathrm{mg} / \mathrm{L}$, as well as negative controls that added sterile water. Plates were incubated at $20^{\circ} \mathrm{C}$ for $6 \mathrm{~h}$. Spore germination was observed by inverted microscope every $3 \mathrm{~h}$, and the germination rate of spore was calculated.

\section{Results}

The inhibition results of the four drugs against $S$. parasitica mycelium growth in two assays are summarized in Table 1 . In the liquid dilution assay, the MIC of MG, CgWE, GA, and TA to $S$. parasitica were $1 \mathrm{mg} / \mathrm{L}, 128 \mathrm{mg} / \mathrm{L}, 512 \mathrm{mg} / \mathrm{L}$, and $32 \mathrm{mg} / \mathrm{L}$, respectively. In the diffusion assay, the data shows that the anti-Saprolegnia effect of the four drugs was concentration-dependent, the MIC of MG, CgWE, GA and TA against S. parasitica was 2 $\mathrm{mg} / \mathrm{L}, 256 \mathrm{mg} / \mathrm{L}, 2048 \mathrm{mg} / \mathrm{L}$, and $128 \mathrm{mg} / \mathrm{L}$, respectively. The growth of $S$. parasitica mycelium was significantly inhibited by GA and TA at concentrations of $1024 \mathrm{mg} / \mathrm{L}$ and $64 \mathrm{mg} / \mathrm{L}$, respectively. The inhibition effects of four drugs on $S$. parasitica mycelium growth are shown in Figure 1 . The highest PIRG (86\%) on S. parasitica mycelium growth was achieved when treated with $\mathrm{CgWE}, \mathrm{GA}$ and TA of $256 \mathrm{mg} / \mathrm{L}, 2048 \mathrm{mg} / \mathrm{L}$, and 128 $\mathrm{mg} / \mathrm{L}$, respectively, in the liquid dilution assay. No higher PIRG was obtained even at higher concentrations of the tested drugs (Fig. 2).

Table 1. Inhibition effects of four drugs on the mycelium growth of S.parasitica

\begin{tabular}{lll}
\hline Drugs & Liquid dilution assay & Agar dilution assay \\
\cline { 2 - 3 } & MIC $(\mathrm{mg} / \mathrm{L})$ & MIC $(\mathrm{mg} / \mathrm{L})$ \\
\hline MG & 1 & 2 \\
CgWE & 128 & 256 \\
GA & 512 & 2048 \\
TA & 32 & 128 \\
\hline
\end{tabular}

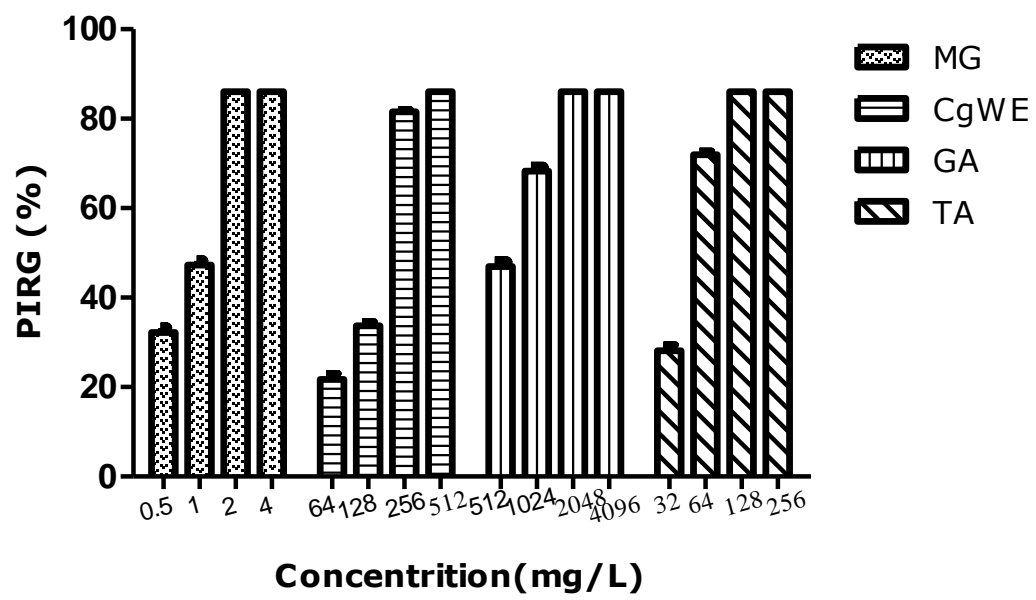

Fig. 2. Inhibition effect of four drugs tested at 4 different concentrations on Saprolegnia mycelium growth at $60 \mathrm{hr}$.

The inhibition results of four drugs to $S$. parasitica zoospore germination in agar dilution assays are summarized in Table 2. In diffusion assay, the MICs of MG, CgWE, GA, and TA to S. parasitica were $2 \mathrm{mg} / \mathrm{L}, 256 \mathrm{mg} / \mathrm{L}, 2048 \mathrm{mg} / \mathrm{L}$, and $128 \mathrm{mg} / \mathrm{L}$, respectively. 
Table 2. Inhibition effects of four drugs on spore development of $S$. parasitica in agar dilution assay

\begin{tabular}{ll}
\hline Drugs & $M I C(m g / L)$ \\
\hline MG & 2 \\
CgWE & 256 \\
GA & 2048 \\
TA & 128 \\
\hline
\end{tabular}

In the liquid dilution assay, zoospore germination was observed under an inverted microscope and the germination rates are shown in Figure 3. The zoospore germination rates in the control group were $80 \%$ and $100 \%$ at $3 \mathrm{~h}$ and $6 \mathrm{~h}$ after inoculation. Significant inhibition of MG, CgWE, GA and TA on the spore germination of $S$. parasitica were achieved at the concentrations of $0.05 \mathrm{mg} / \mathrm{L}, 50 \mathrm{mg} / \mathrm{L}, 50 \mathrm{mg} / \mathrm{L}$, and $5 \mathrm{mg} / \mathrm{L}$, respectively and above (Fig. 3 ).
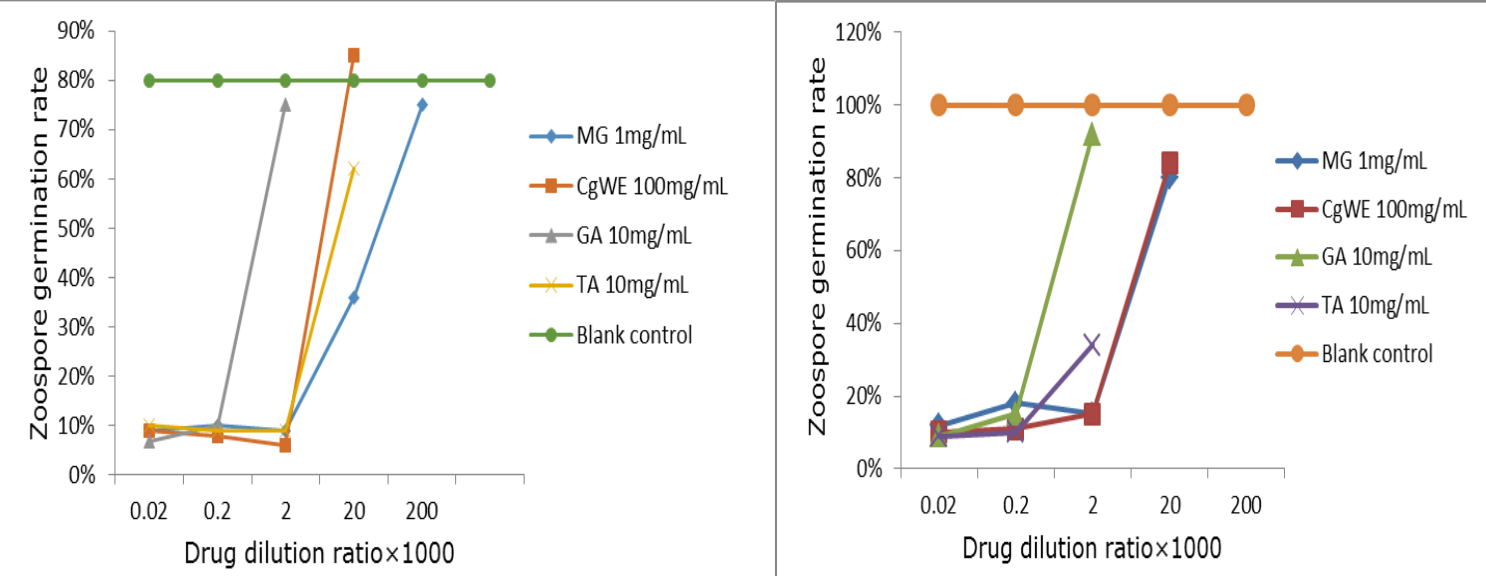

Fig. 3. Inhibition effects of four drugs on spore germination of S.parasitica after $3 \mathrm{~h}$ (left) and $6 \mathrm{~h}$ (right) exposure.

\section{Discussion}

In this study, we have shown for the first time that treatment with Chinese gall and its major components GA and TA inhibited mycelial growth and spore germination of Saprolegnia under laboratory conditions. The results of this study strongly suggest that the three tested drugs derived from the Chinese gall possess a dose-dependent antifungal effect.

A previous study showed that Chinese gall inhibited the growth of $V$. parahaemolyticus and L. monocytogenes both in broth and agar media assays (Wu, 2014). Chinese gall has been found to control saprolegniasis effectively whether separately or combined with derris dust and toosendanin (Du et al., 2015). In in vitro experiments, Chinese gall displayed bacteriostatic or bactericidal activity against Staphylococcus aureus, Streptococcus, Pneumococcus, and Salmonella typhi, Bacillus dysentery, Bacillus anthracis, Diphtheria, and Pseudomonas aeruginos (Fang et al., 2009). The tannic fractions from anacardium humille have shown antibacterial activity against Staphylococcus aureus, Pseudomonas aeruginosa, and Enterococcus faecalis (Ferreira (Ferreira et al., 2012). Scalbert (1991) proposed different mechanisms to explain tannin antibacterial activity. On one hand, tannins were able to react and precipitate with proteins and other nitrogen compounds. On the other hand, tannins could chelate metal ions, reducing their access to microorganisms. The same theory may apply to its antifungal activity. There have been no applied research reports relating to tannic acid in aquaculture.

In the agar diffusion and liquid dilution assay, we found that the spores were more sensitive than mycelium to the four drugs. 
The MIC values obtained in the liquid dilution assay that inhibited the mycelial growth and zoospore germination were lower than those obtained in the agar assay. In our study, the experimental drugs derived from Chinese gall showed that antifungal activity against $S$. parasitica could not reach complete inhibition, indicating a fungistatic rather than the fungicidal activity of $\mathrm{CgWE}, \mathrm{GA}$, and TA at the concentrations tested. In agar diffusion and liquid dilution assay, the malachite green effectively inhibited the growth of $S$. parasitica respectively at $2 \mathrm{mg} / \mathrm{L}$ and $1 \mathrm{mg} / \mathrm{L}$, respectively; the minimal zoospore germination inhibitory concentration was $2 \mathrm{mg} / \mathrm{L}$ and $0.05 \mathrm{mg} / \mathrm{L}$. In agar dilution assays, the MIC of CgWE to the zoospores was $256 \mathrm{mg} / \mathrm{L}$ and differed from the research results of Zhang shiqi (Zhang et al. 2011). This may be due to the difference between the origin of the herb and the type of Saprolegnia. The MIC of GA to hypha and spore of $S$. parasitica was $2048 \mathrm{mg} / \mathrm{L}$ both in the agar and liquid dilution assay, which is significantly higher than $\mathrm{CgWE}$, indicating that GA may not be the main active ingredient of Chinese gall. Tannic acid, at the concentration of $128 \mathrm{mg} / \mathrm{L}$ or $32 \mathrm{mg} / \mathrm{L}$, inhibited the growth of $S$. parasitica mycelium effectively and significantly inhibited spore germination of $S$. parasitica at the concentration of $128 \mathrm{mg} / \mathrm{L}$ or $5 \mathrm{mg} / \mathrm{L}$. The MIC of TA was a quarter to one-sixteenth of those of CgWE and gallic acid, showing potential utility on controlling $S$. parasitica infection and confirming that it was TA that plays an important role in Chinese gall in terms of inhibiting S. parasitica (Liu et al., 2015).

In this study, the fungistatic properties of TA against $S$. parasitica were determined for the first time. Considering its low effective bacteriostatic concentration and significant antifungal effect, it appears that TA has better research and developmental prospects in the prevention and control of water molds and can provide a reference for screening and studying new fungal drugs.

The fungistatic mechanism of Chinese gall and its extracts was not explored in this study, but it was determined by other research (Goel et al., 2005) where it was suggested that the reduction of enzyme activity, cell membrane dysfunction, and deprivation of substrate, metal ions and minerals may be the major mechanisms. The capacity of fish to survive the different doses of TA was not tested. Further study is required to illuminate the precise antifungal mechanism, the relationship of TA between structure and function and the capacity of fish to survive the different doses of three drugs. Although this is a pilot study, our findings provided insights into the importance of TA in the control of $S$. parasitica infection in aquaculture.

\section{Acknowledgments}

This work was supported by grants from the Key Laboratory of Fishery Drug Development and Key Laboratory of Aquatic Animal Immune Technology, Ministry of Agriculture (201503), FEBL project (2019FBZ04), Jiangsu Marine and Fisheries Bureau project (D2017-3). We are grateful to Pro. Yang X.L. for generously donating $S$. parasitica type strain.

\section{References}

Andrade Jr R.G., Dalvi L.T., Silva Jr J.M.C., Lopes G.K., Alonso A., Hermes-Lima M.J.A.o.B., 2005. The antioxidant effect of tannic acid on the in vitro copper-mediated formation of free radicals. Archives of Biophysics., 437(1): 1-9.

Du Y.C., Liu N., Li B., Shi X., 2015. Screening of anti-saprolegnia drugs in Varicorhinus macrolepis. Beijing Agricultural., 8:79-80.

Fang T., Bo L., Ji B., Zhang G., Luo Y., 2009. Identification and structure-activity relationship of gallotannins separated from Galla chinensis, LWT-Food Sci Technol., 42(7): 1289-1295.

Ferreira P.R.B., Mendes C.S.O., Rodrigues C.G., Rocha J.C.M., Royo V.D.A., Valério H.M., Oliveira D.A.D., 2012. Antibacterial activity tannin-rich fraction from leaves of Anacardium humile, Ciência Rural., 42(10): 1861-1864.

Goel G., Puniya A.K., Singh K., 2005. Tannic acid resistance in ruminal streptococcal isolates. Journal of Basic Microbiology: An Int J Biochem Physiol Gen Morphol Ecol Microorg., 45(3): 243-245.

Hussein M.M., Hatai K., 2002. Pathogenicity of Saprolegnia species associated with outbreaks of salmonid saprolegniosis in Japan. Fish Sci., 68(5): 1067-1072. 
Liu Y.T., Ai X.H., Yang Q.H., Xu N., 2015. Study on the inhibition effect on two Saprolegnia with supercritical $\mathrm{CO} 2$ fluid extracts from 15 Chinese herbal medicines. Freshwater Fish., 45 (3):40-45.

Meyer F.P., Jorgenson T.A., 1983. Teratological and Other Effects of Malachite Green on Development of Rainbow Trout and Rabbits. Trans American Fish Soc., 112(6): 818824.

Neish G.A., Hughes G.C., 1980. Diseases of fishes. Fungal Diseases of Fishes. Neptune, New Jersey: T.W.F Publications. pp. 159.

Orlowski P., Tomaszewska E., Gniadek M., Baska P., Nowakowska J., Sokolowska J., Nowak Z., Donten M., Celichowski G., Kezyzowska M., 2014. Tannic acid modified silver nanoparticles show antiviral activity in herpes simplex virus type 2 infection. PloS One., 9(8): e104113.

Pérez-Fonseca A., Alcala-Canto Y., Salem A.Z., Alberti-Navarro A.B., 2016. Anticoccidial efficacy of naringenin and a grapefruit peel extract in growing lambs naturally-infected with Eimeria spp. Vet Parasitol., 232: 58-65.

Pottinger T.G., Day J.G., 1999. A Saprolegnia parasitica challenge system for rainbow trout: assessment of Pyceze as an anti-fungal agent for both fish and ova. Dis Aquat Organ., 36(2): 129-141.

Qiao C.Y., Li J.K., 2011. The research progress of Chinese gall and gallotannin. Science Technolog., 7:458-462.

Scalbert A., 1991. Antimicrobial properties of tannins. Phytochemistry., 30(12): 38753883.

Shin S., Kulatunga D.C.M., Dananjaya S.H.S., Nikapitiya C., Lee J., De Zoysa M., 2017. Saprolegnia parasitica Isolated from Rainbow Trout in Korea: Characterization, Anti-Saprolegnia Activity and Host Pathogen Interaction in Zebrafish Disease Model. Mycobiology., 45(4): 297-311.

Srivastava S., Sinha R., Roy D., 2004. Toxicological effects of malachite green. Aquatic toxicol., 66(3) :319-329.

Webster J., 1998. Fungi and Fish Diseases, LG Willoughby, illus.(Softcover). ISBN 0 95211981, Pisces Press, Stirling, Scotland (1994), p.57.

Wu J., 2014. Inhibiting Listeria monocytogenes, Vibrio parahaemolyticus and Morganella morganii with Aqueous Methanol Extracts of Punica granatum and Galla chinensis. (Doctoral dissertation, Virginia Tech.)

Zhang S.Q., 2011. The screening for the anti-Saprolegnia drugs and application effects of the preparation. Shanghai Ocean University.

Zheng S.M., Huang J.J., Qing W.U., Sha S.J.A.H.S., 2010. StudieS on separation and antibacterial activity of the effective components of Chinese herbal compounds gallnut for fishery antimicrobial agent. Acta Hydrobiologica Sinica., 34(1):57-64. 